\title{
Sedentary Death Syndrome
}

\author{
Simon J. Lees ${ }^{1}$ and Frank W. Booth ${ }^{1,2}$
}

\section{Catalogue Data}

Lees, S.J.; and Booth, F.W. (2004). Sedentary death syndrome. Can. J. Appl. Physiol. 29(4): 447-460. (C) 2004 Canadian Society for Exercise Physiology.

Key words: physical inactivity, chronic diseases, diabetes, glucose

Mots-clés: l'inactivité physique, maladies chroniques, le diabète, glucose

\begin{abstract}
Résumé
Sedentary death syndrome (SeDS) is a major public health burden due to its causing multiple chronic diseases and millions of premature deaths each year. Despite the impact of physical inactivity, very little is known about the actual causes of physical inactivity-induced chronic diseases. It is important to study the mechanisms underlying molecular changes related to physical inactivity in order to better understand the scientific basis of individualized exercise prescription and therapies for chronic diseases, and to support improved public health efforts by providing molecular proof that physical inactivity is an actual cause of chronic diseases. Physical activity has a genetic basis. A subpopulation of genes, which have functioned to support physical activity for survival through most of humankind's existence, require daily exercise to maintain long-term health and vitality. Type 2 diabetes (T2D) is an example of a SeDS condition, as it is almost entirely preventable with physical activity. To determine the true role of physical inactivity in the development and progression of $T 2 D$, information is presented which indicates that comparisons should be made to physically active controls, rather than sedentary controls, as this population is the healthiest. Use of sedentary subjects as the control group has led to potentially misleading interpretations. If physically active individuals were designated as the contral group, a different interpretation would have been drawn. It is thought that there is no difference in GLUT4 concentration between T2D and sedentary groups. However, GLUT4 expression is higher in active controls than in sedentary and T2D groups. Therefore, to obtain causal mechanisms for SeDS in order to allow for scientifically based prevention and therapy strategies, physically active subjects must serve as the control group.
\end{abstract}

${ }^{1}$ Dept. of Biomedical Sciences, and ${ }^{2}$ Dept. of Medical Pharmacology and Physiology and Dalton Cardiovascular Center, Univ. of Missouri-Columbia, Columbia, MO 65211. 
Le syndrome de la mort par sédentarité (SeDS) provoque de nombreuses maladies chroniques et des millions de décès prématurés chaque année. De ce fait, il est devenu un des problèmes majeurs de santé publique. Bien que nous sachions l'impact de l'inactivité physique, nous connaissons très peu les mécanismes inducteurs des maladies chroniques. L'étude des mécanismes de modification moléculaire associée à l'inactivité physique s'avère primordiale afin de mieux comprendre les bases scientifiques de la prescription individualisée d'exercice physique et du traitement des maladies chroniques. L'élaboration d'une preuve moléculaire que l'inactivité physique est vraiment une cause de maladie chronique viendrait soutenir les efforts déjà effectués pour améliorer la santé publique. On connaît bien la base génétique de l'activité physique: une sous-population de gènes, présente depuis l'apparition de l'homme sur terre, a pour fonction d'appuyer l'activité physique comme moyen de survie. Cependant, cette fonction requiert l'exercice physique de façon quotidienne afin d'assurer la santé à long terme et la vitalité. Pour illustrer notre propos, le diabète de type 2 (T2D) représente un bon exemple de la problématique du SeDS, carl'activité physique peut presque entièrement le prévenir. Afin d'établir le rôle exact de l'inactivité physique dans la manifestation et l'évolution du T2D, l'analyse indique qu'il faut comparer les diabétiques à des gens actifs physiquement, car ces derniers sont en meilleure santé que des individus sédentaires. Le recours à des individus sédentaires dans un groupe de contrôle a conduit à de mauvaises interprétations. Un groupe de contrôle constitué d'individus physiquement actifs auraient amené des conclusions fort différentes. Néanmoins, on pense à tort qu'il n'y a pas de différence de concentration de GLUT4 entre les T2D et les individus sédentaires. Toutefois, l'expression de GLUT4 est plus importante chez les individus actifs que chez les T2D et les sédentaires. Par conséquent, pour identifier les mécanismes à la base du SeDS et pour avancer des preuves scientifiques concernant les stratégies de prévention et de traitement, les individus physiquement actifs devraient constituer le groupe de contrôle.

\section{Introduction: Inactivity is an Actual Cause of Death}

It seems as if the only thing that is constant is change. Throughout history, emerging diseases have continued to present the challenge to find preventions and cures. Examples are Poliomyelitis, Malaria, Tuberculosis, Severe Acute Respiratory Syndrome (SARS), West Nile Virus, new flu strains, Acquired Immune Deficiency Syndrome (AIDS), and the Sedentary Death Syndrome (SeDS). Recent examples are SARS, West Nile Virus, new flu strains, and SeDS. We estimate that 334,144 premature deaths were the result of physical inactivity in the U.S. in 2000 (Chakravarthy and Booth, 2003). The U.S. Centers for Disease Control (CDC) has reaffirmed our estimate. In 1986 a total of 256,686 deaths in the U.S. were due to "no regular exercise" (Hahn et al., 1990). Since the prevalence of obesity and type 2 diabetes (T2D) has doubled in the U.S. in the last 20 years, the 256,686 deaths in 1986 due to "no regular exercise" are likely an underestimation of 2004.

The CDC in 2004 published the finding that actual deaths from poor diet and physical inactivity increased by $1 / 3$ from 300,000 to 400,000 individuals annually, or $16 \%$ of all deaths in the U.S., from 1990 to 2000 (Mokdad et al., 2004). The World Health Organization (WHO) in 2002 estimated that there are 2 million premature deaths worldwide each year from physical inactivity. Physical inactivity should therefore be a major public health concern, but it is not. To draw greater attention to the epidemic of physical inactivity, the term SeDS was coined to emphasize that sedentary living increases the prevalence of premature death. 
Contributing to premature deaths is that fact that physical inactivity leads to an increased prevalence of over 25 chronic diseases, including heart disease (Chakravarthy and Booth, 2003). Further, the actual cause of death is not necessarily obesity, heart disease, or T2D, but often the modifiable behavioral risk factors (such as physical inactivity) that lead to the onset of disease. In 1986 for example, $35 \%(205,254$ deaths) of the total deaths from coronary heart disease (CHD) involved persons with "no regular exercise" (Hahn et al., 1990). Only 25\% of CHD were associated with tobacco. Therefore, the actual cause of death for these 205,254 individuals was physical inactivity leading to CHD.

\section{Inactivity is the Cause of Many Chronic Diseases}

Physical inactivity is one of three modifiable lifestyle risk factors, which are the main actual causes of most chronic diseases, the other two being poor diet and smoking. Chronic diseases are a major cause of death-including cardiovascular conditions, diabetes, stroke, cancers, and respiratory diseases-which account for $59 \%$ of the 56.5 million deaths worldwide annually, and $45.9 \%$ of the global disease burden (World Health Organization, 2004). Chronic diseases accounted for $76 \%$ of health care costs in the U.S. in 1987 (Hoffman et al., 1996). Thus chronic diseases are a major burden to humankind. Therefore, as one of the three major contributing factors, physical inactivity is a major burden to humankind.

\section{INACTIVITY AS A MODIFIABLE RISK FACTOR FOR CHRONIC DISEASES}

Despite the fact that these risk factors are largely within the control of individuals in developed nations, there is an overwhelming prevalence of poor lifestyle choices in these populations. In terms of physical activity, Health Canada recommends 30 to 60 minutes of moderate-intensity physical activity 4 to 7 days per week. The CDC recommends 30 minutes or more of moderate-intensity physical activity on most, preferably all, days of the week. It is estimated that $62 \%$ of Canadians (Craig et al., 1999) and more than $60 \%$ of Americans are physically inactive (Centers for Disease Control and Prevention, 2003). It has been shown that individuals who exercise more than the minimum recommendations offered by the CDC have a $30 \%$ reduced risk of coronary artery disease, stroke, and T2D (Hu et al., 1999; 2000; Manson et al., 1999).

\section{Mechanisms of Chronic Diseases Leading to SeDS}

\section{BASIS FOR A HIGHER COMPLIANCE TO A PHYSICALLY ACTIVE LIFESTYLE}

Despite overwhelming evidence of the benefits of physical activity, very little is known about the mechanisms involved in the actual causes of physical inactivityinduced chronic diseases. Since many of the molecular mechanisms by which physical activity treats a disease differ from those through which physical inactivity is the actual cause of the disease, it is inappropriate to the well-being of the patient to rely solely on the mechanisms of exercise treatment to individualize exercise prescription. Rather, exercise prescription must also include knowledge of the actual molecular causes of the disease, i.e., physical inactivity. For example, an AIDS 
vaccine cannot be made as well if the actual molecular cause of AIDS is unknown. Likewise, it is contended that unless the molecular basis of physical inactivityinduced chronic disease is known, prevention and treatment of specific chronic diseases with individualized exercise prescription will be less effective, if not impossible.

A question then becomes, are there other reasons why is it important to know the molecular cause of a chronic disease before prescribing treatment? One answer might be that the lack of known molecular disease mechanisms from physical inactivity contributes to a greater percentage of individuals in Canada and the U.S. being sedentary than if molecular links from physical inactivity to chronic disease were available to drive public health efforts. One example is the publication (Denissenko et al., 1996) providing a direct etiological link between a defined chemical carcinogen in cigarette smoke and human cancer. This was associated with subsequent anti-smoking policies, inducing tobacco companies to switch TV ads from claims that there is no scientific evidence that cigarettes cause disease to admissions by the same companies that smoking does cause disease. Further, once mechanisms of physical inactivity-induced chronic diseases are delineated, early detection of biomarkers may become valuable tools of preventive medicine (Licinio et al., 2004).

Therefore, the actual molecular cause of inactivity-related diseases should have an impact. Future research in exercise physiology must recognize the following. Exercise is a treatment to attenuate disease symptoms, whereas physical inactivity is the actual cause of the disease (Figure 1). There are numerous excellent reviews (Hamdy et al., 2001; Henriksen, 2002; Wallberg-Henriksson et al., 1998) on exercise treatments applied to sedentary animals/humans. Exercise research designs are not set up to study mechanisms of chronic diseases, but to study mechanisms of the reversal of disease. Furthermore, mechanisms of exercise treatment are not $100 \%$ identical to those by which physical inactivity causes disease.

Scientifically based preventions and treatments must be based on an understanding of the molecular basis by which physical inactivity interacts with genes and gene polymorphisms to cause a threshold of biological significance to be attained so that overt clinical chronic disease occurs. Since individuals vary in polymorphisms, exercise prescriptions will require individualization in the future. However, if we do not know which genes produce chronic diseases from physical inactivity, it will be impossible to evaluate the interaction of physical inactivity with disease-predisposing polymorphisms. The purpose of this review, then, is to discuss the role exercise physiology should play in determining the actual causal links between physical inactivity, chronic disease, and SeDS.

\section{MALADAPTATION TO PHYSICAL INACTIVITY IS GENETICALLY BASED}

In order to value the manifestation of genes responsible for the clinical symptoms due to physical inactivity, we must first appreciate the concept that our bodies were made to expect daily exercise (Astrand and Rodahl, 1986). Most of our genetic evolution occurred under a level of physical activity higher than in today's sedentary culture. Human genetic evolution has largely occurred in conjunction with a lifestyle based on hunting and gathering. From about 2 million years before present (b.p.), during the transition from Australopithecus to Homo erectus until 


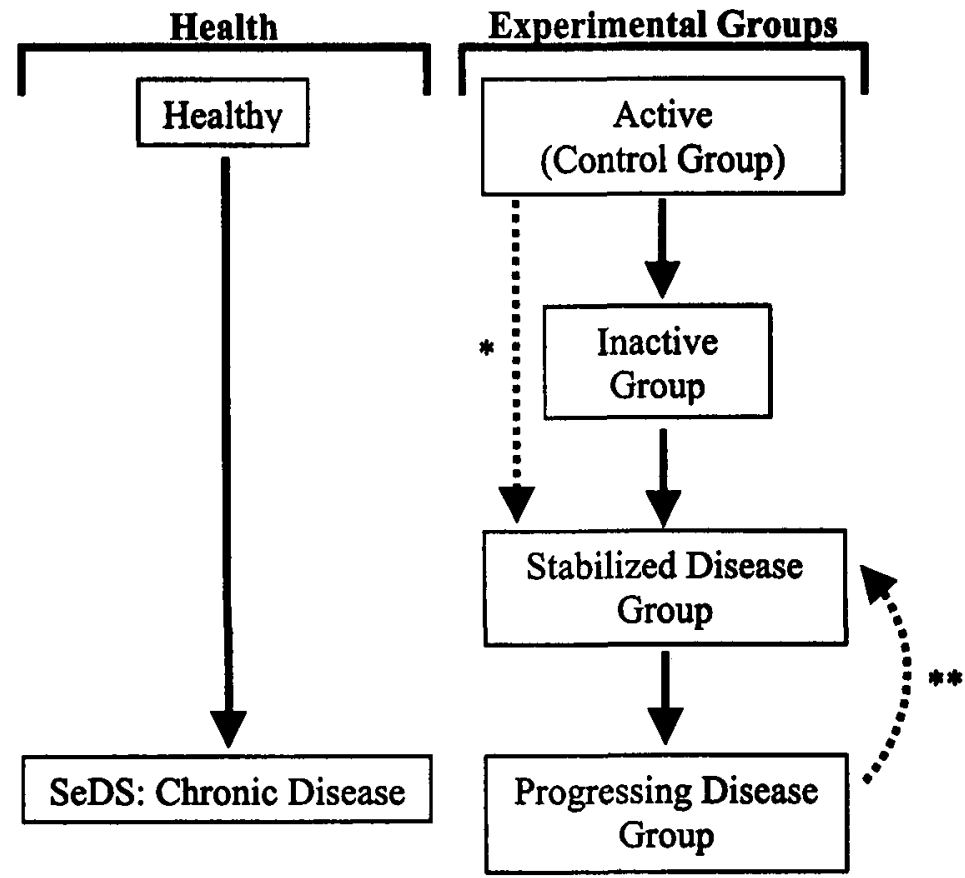

Figure 1. Schematic representation demonstrating that the "healthiest" group is the most active group. The inactive control group is an intermediate group between the healthiest and the diseased groups. Therefore, the onset of disease is actually initiated as a result of physical inactivity. *Smaller proportion of individuals susceptible to chronic disease despite an active lifestyle. ${ }^{*}$ Exercise treatment is sometimes effective in stabilizing symptoms of chronic disease by improving or reversing some symptoms of progressing chronic disease in order to stabilize.

the end of the Paleolithic era (12,000 b.p.), the human genome evolved under conditions in which survival depended on the hunting and gathering of food. The physical demands of such a lifestyle were certainly strenuous, as are apparent in the musculoskeletal adaptation found in archeological remains of these individuals. This activity and feeding pattern evoked gene selection in order to optimize survival under these conditions (Clastres, 1972).

At the end of the Paleolithic era, Homo sapiens was beginning to domesticate animals and develop agriculture. However, since the beginning of the industrial revolution, there has been an ever growing divergence between the conditions under which our genome evolved and the way society lives today (e.g., the advent of the steam engine in 1705 and the internal combustion engine in 1860, followed by automobiles and tractors). In other words, genetic evolution has not changed as rapidly as social evolution and trends of physical inactivity over the last 40 to 100 years. The human genome requires physical activity to lower the prevalence of many chronic diseases. 
For hunter-gatherers, food procurement was directly related to physical exertion. Estimated energy expenditure attributed to physical activity (PA-EE) averaged 19.6-24.7 kcal/ $\mathrm{kg}$ per day for men and $14.6 \mathrm{kcal} / \mathrm{kg}$ per day for women in hunter-gatherer societies, while estimates for modern sedentary office workers are $4.4 \mathrm{kcal} / \mathrm{kg}$ per day for men and $4.2 \mathrm{kcal} / \mathrm{kg}$ per day for women (Cordain et al., 1997). This comparison is not limited to differences between the past and present. Aerobic fitness in modern forager populations is about $40 \%$ higher than that of modern affluent society (Cordain et al., 1997). Currently, children in the U.S. spend an average of 40 hours per week watching television (Dietz and Gortmaker, 1995) and 25 hours per week in the classroom. In the 1950 s children averaged 10 hours per week with TV (Kraus and Raab, 1961). With the majority of North Americans leading a physically inactive lifestyle and a society that perceives exercise as a burden rather than necessity, all available-not selective-countermeasures must be used to increase daily physical activity. If current selective methods were completely effective, SeDS would not be killing $>300,000$ in the U.S. annually. Scientifically based exercise prescription is currently not based on the actual molecular causes of disease from physical inactivity.

As late as the middle of the 20th century, modern hunter-gatherer societies still existed that had minimal influence from Western society. These hunter-gatherer societies included the Canadian Igloolik Inuit and other indigenous populations of the circumpolar regions. In several studies comparing these populations to Western populations, it has been shown that there is a much lower incidence of chronic diseases and their biomarkers, including deficiency in lean body mass (Rode and Shephard, 1994), adiposity (Glanville and Geerdink, 1970), coronary heart disease (Bjerregaard and Dyerberg, 1988; Kromann and Green, 1980; Lederman et al., 1962; Middaugh, 1990), diabetes (Kromann and Green, 1980) and insulin resistance (Joffe et al., 1971; Kuroshima et al., 1972; Lindeberg et al., 1999; Merimee et al., 1972; Spielman et al., 1982). In fact, there is evidence that certain populations in Canada who have only recently adopted a more sedentary Western lifestyle have had an alarming increase in T2D (Rode and Shephard, 1994). Further, over a 10-year period of exposure to Western society from 1970-71 to 1980-81, the Canadian Igloolik Inuit have shown a 15\% decrease in predicted $\mathrm{VO}_{2} \max$ (Rode and Shephard, 1984). Clearly, the adoption of a physically inactive lifestyle has had rapid and dramatic health consequences on these populations.

\section{ONE ACTUAL CAUSE OF A SEDS CONDITION}

As the purpose of this review is to discuss the role exercise physiology should play in determining the actual causal links between physical inactivity, chronic disease, and $\mathrm{SeDS}$, one aim of this review is to illustrate an appropriate scientific approach to determine a causal link between physical inactivity and chronic disease. The specific example will be T2D. T2D is largely a human-made worldwide pandemic. In 2000 the WHO estimated that over 176 million people in the world have diabetes. According to the Canadian Diabetes Association, over 2 million Canadians have T2D. The WHO projects that the number of Canadians with T2D will rise to over 3.5 million by the year 2030 . Further, once a person develops diabetes, it is 
incurable and progresses to cause other serious diseases/complications such as cardiovascular disease, kidney disease, blindness, and conditions that may require amputation. It is estimated that the cost of treating individuals with diabetes and its complications in Canada is at least 9 billion (\$U.S.) (Health Canada). Despite the severity of T2D, both as a disease and in its prevalence, little is known about the cellular and molecular mechanisms from physical inactivity that lead to its onset.

Available data suggest that $\sim 90 \%$ of T2D is largely preventable by a physically active lifestyle. Epidemiological information supports the conclusion that physical inactivity plays an important role in the development of T2D. From 1958 to 1998 the number of diagnosed cases of T2D in the U.S. rose from 1.3 million to 10 million. Because genes and gene polymorphisms have not changed in the last 40 years, the increased incidence of T2D has to be completely explained by the changes in environmental modulation of genes predisposing to T2D (for review, see Diamond, 2003).

Regular physical activity is required to maintain optimal insulin-stimulated glucose uptake. Physically trained individuals have a markedly blunted insulin response to a glucose load and yet have normal plasma glucose concentration at rest (Seals et al., 1984). However, the residual effects of the last bouts of exercise have been shown to play an important role in the training adaptation. Heath et al. (1983) found that when 8 well-trained subjects stopped training for 10 days, their $\mathrm{VO}_{2} \mathrm{max}$, estimated percent body fat, and body weight did not change. The maximum rise in plasma insulin concentration in response to a 100-g oral glucose load was $100 \%$ higher after 10 days without exercise than when they were exercising regularly. Despite the increased insulin levels, blood glucose concentrations were higher after 10 days without exercise. Amazingly, one bout of exercise after 11 days without exercise almost returned the subjects' insulin and glucose responses to an oral 100-g glucose load to the initial "trained" value. Thus we must consider levels of physical activity when assigning "healthy" subjects to a control group.

Impaired glucose tolerance is not an inevitable consequence of aging, as believed in the medical community (Resnick, 1998). Rather, insulin resistance and glucose intolerance are an inevitable consequence of physical inactivity. Seals et al. (1984) reported the absence of glucose intolerance in highly active 60-year-old men. Glucose tolerance was similar between three groups: active, young (endurance trained, $26 \pm 1 \mathrm{yr}, \mathrm{VO}_{2} \max : 65.8 \pm 1.6 \mathrm{ml} \cdot \mathrm{kg}^{-1} \cdot \mathrm{min}^{-1}$ ), sedentary, young (untrained, $28 \pm 1 \mathrm{yr}, \mathrm{VO}_{2} \max : 44.4 \pm 1.3 \mathrm{ml} \cdot \mathrm{kg}^{-1} \cdot \mathrm{min}^{-1}$ ), and active, older subjects (masters athletes, $60 \pm \mathrm{yr}, \mathrm{VO}_{2} \max : 52.9 \pm 1.6 \mathrm{ml} \cdot \mathrm{kg}^{-1} \cdot \mathrm{min}^{-1}$ ). However, insulin resistance differed between the three groups. The insulin response to the glucose tolerance test was three times higher for the sedentary, young group compared to both the active, young and older groups. Young, sedentary subjects had two- and five times greater plasma glucose and insulin responses, respectively, than did either the active, young or the active, older group. These data clearly demonstrate that aging is not the sole factor determining onset of glucose intolerance and insulin resistance, since young, sedentary men were already insulin resistant while older, active men were not. These early studies by Heath et al. (1983) and Seals et al. (1984) provide convincing data that physical activity is a crucial element in regulating optimal glucose tolerance and insulin sensitivity. 


\section{INSULIN-MEDIATED SIGNALING OF GLUCOSE UPTAKE}

An important role for physical activity in insulin-mediated glucose uptake was established above. Glucose transport into skeletal muscle is accomplished via facilitated diffusion, and insulin-stimulated muscle glucose transport activity is considered the rate-controlling defect (Perseghin et al., 2003). GLUT4 is the major isoform of glucose transporter carrier proteins present in mouse, rat, and human skeletal muscles. GLUT4 translocation to the plasma membrane is needed for glucose transport into skeletal muscle. Furthermore, GLUT4 activity in the sarcolemma may be regulated by insulin through p38 MAPK (Lemieux et al., 2003; Somwar et al., 2000).

Normal insulin stimulation of glucose transport is as follows: When insulin binds the insulin receptor, the result is an autophosphorylation of the $\beta$ subunit and activation of intrinsic tyrosine kinase activity (for review, see Cheatham and Kahn, 1995). Activation of the insulin receptor initiates a cascade of events including the phosphorylation of downstream targets such as insulin receptor substrate (IRS) proteins. These proteins then facilitate the activations of phosphatidylinositol 3kinase (PI3K) and protein kinase B/Akt (PKB), initiating GLUT4 translocation from an intracellular storage site to the plasma membrane. Protein kinase $\mathrm{C}(\mathrm{PKC})$ also may have a putative role in GLUT4 translocation (for reviews, see Elmendorf, 2002; Tomas et al., 2002).

To date, several points in the insulin signaling pathway that mediate skeletal muscle glucose uptake are recognized to be adversely affected in persons with T2D and obesity: decreased insulin receptor tyrosine kinase activity, decreased insulin receptor substrate-1 (IRS-1) tyrosine phosphorylation, and decreased insulin-stimulated PI3K activation (Bjornholm et al., 1997; Caro et al., 1987; for review, see Zierath et al., 1998). Many of these studies used a group of sedentary controls without T2D as the point of comparison for interpretations of the effect of T2D on insulin-mediated glucose signaling.

\section{The Healthy Group Should be Assigned as the Control}

It is dogma in medicine that healthy individuals serve as the control group and that sick patients serve as the treatment group. When studying T2D, standards of insulin sensitivity and glucose tolerance have been used to determine group assignment of a subject, usually without reference to his or her initial level of physical activity. As a rule, subjects have been assigned to one of two groups: a T2D group or a "healthy control" group whose activity levels were usually not designated. Group assignment of subjects is a vital aspect of experimental design, as it determines interpretation of data and conclusions. A reanalysis of the interpretation of published data from T2D studies in which controls are now divided into inactive and active controls has produced different conclusions than those commonly found in most publications on T2D.

The remainder of this review reanalyzes selected examples of previous publications of the T2D studies. The general theme for the outcome of the reanalysis is that active controls usually have superior insulin-mediated cell signaling than inactive controls, with the signaling component of inactive controls either being similar, or greater than, T2D. The significance of reinterpretations using an active 
control group is that the effect of physical inactivity and T2D on insulin-mediated signaling is often underestimated.

\section{INSULIN-MEDIATED GLUCOSE UPTAKE}

Zierath et al. (1996) found no differences in whole-body insulin-mediated glucose uptake and in basal GLUT4 protein in the vastus lateralis muscle between the T2D and sedentary controls. The T2D group consisted of 55-year-old subjects $\left(\mathrm{VO}_{2} \mathrm{max}\right.$ $=30.5 \mathrm{ml} \cdot \mathrm{kg}^{-1} \cdot \mathrm{min}^{-1}$ ) and "healthy controls" included individuals who were 54 years old $\left(\mathrm{VO}_{2} \max =28.0 \mathrm{ml} \cdot \mathrm{kg}^{-1} \cdot \mathrm{min}^{-1}\right)$. On the other hand, masters athletes (age $60 ; \mathrm{VO}_{2} \max =52.9 \mathrm{ml} \cdot \mathrm{kg}^{-1} \cdot \mathrm{min}^{-1}$ ) had $30 \%$ and $41 \%$ of the areas under the glucose and insulin curves, respectively, during an oral glucose tolerance test (Seals et al., 1984), implying that the active control group had increased whole-body insulin-mediated glucose uptake compared to lean untrained age-matched controls. Designation of the activity level of the control group in 50-to 60-year-old subjects is important to the outcome of the interpretation. If the control group is active, the interpretation becomes that physical inactivity lowers insulin-mediated glucose uptake to a level similar to T2D. On the other hand, if the control group is physically inactive, the interpretation in the Zierath et al. (1996) study becomes that T2D does not lower insulin-mediated glucose from control levels. While the former interpretation would support physical inactivity as a cause of insulin resistance with aging, the latter interpretation would not. For the above example, selection of an active group as the control allows the observation of inactivity-associated onset of disease.

\section{GLUT4}

It is commonly reported that skeletal muscle GLUT4 content is the same in subjects with T2D as control sedentary subjects (Andersen et al., 1993; Friedman et al., 1992; Garvey et al., 1992; Pedersen et al., 1990). However, it is well established that training of sedentary subjects increases GLUT4 protein, implying that physical inactivity causes GLUT4 expression to be attenuated in sedentary subjects. Voluntary wheel running induced a $50 \%$ increase in GLUT4 protein in rat epitrochlearis muscle (Rodnick et al., 1992), and treadmill training induced a $47 \%$ increase in GLUT4 protein in rat soleus muscle and a $38 \%$ increase in GLUT4 mRNA in rat gastrocnemius muscle (Kim et al., 1999a; Slentz et al., 1992). Similar findings have been extended to humans. For example, Langfort et al. (2003) found that GLUT4 expression is $36 \%$ higher in the trained leg compared to the contralateral untrained leg in lean, young, healthy males. Thus, different interpretations and conclusions are dependent upon whether the control group is active with less chronic disease or the sedentary group with more chronic disease.

If active subjects were to have been used as the control group, then a likely interpretation would be that subjects with T2D would have had a lower GLUT4 protein content than control. However, if inactive controls were the comparison, the prevalent conclusion would be that T2D does not affect GLUT4 expression, and inactivity as an initiator of cellular and molecular mechanisms for T2D would be underemphasized, as is the current situation. A better approach to control groups is illustrated in Figure 1. The physically active group as the healthiest population 
from chronic diseases is shown as normal. Physical inactivity lowers health and is the sedentary group. Sufficient inactivity will induce genes predisposing to a chronic disease to produce proteins whose integrated function causes passage through a biological threshold to overt clinical disease. Exercise is prescribed as a treatment to prevent further disruptions in homeostasis.

Utilization of a sedentary group as the control group misses inactivityinduced decreases in GLUT4 expression from an active control group. Since inactivity is one actual cause of events initiating muscle GLUT4 to decrease, and the GLUT4 deficiency may be a mediating factor in the progression to prediabetes, important causal information may be missed when calling sedentary individuals as the healthiest normal group.

\section{INSULIN RECEPTOR SUBSTRATE 1 (IRS-1) AND PHOSPHATIDYLINOSITOL} 3-KINASE (PI3K)

IRS-1 and PI3K are both downstream signaling molecules of the insulin receptor that are involved in insulin-stimulated GLUT4 translocation to the plasma membrane. However, unlike GLUT4 content, insulin-stimulated IRS-1 phosphorylation and IRS-1-associated PI3K activity have been shown to be lower in T2D compared with a presumably sedentary control group (no physical activity levels were reported) (Bjornholm et al., 1997). Bjornholm et al. (1997) reported an approximately six-fold increase in insulin-stimulated IRS-1 phosphorylation in the control group (age $55 \pm 3 \mathrm{yrs}$; BMI $27.5 \pm 1.2 \mathrm{~kg} / \mathrm{m}^{2}$ ) compared to basal levels, while there was no difference in insulin-stimulated IRS-1 phosphorylation in the T2D group (age $56 \pm 3 \mathrm{yrs} ; \mathrm{BMI} 27.1 \pm 2.0 \mathrm{~kg} / \mathrm{m}^{2}$ )

Without considering the adaptive response due to exercise training, the magnitude of decreases in this signaling pathway likely has been underestimated. For example, Luciano et al. (2002) reported an approximately six-fold increase in insulin-stimulated IRS-1 tyrosine phosphorylation in sedentary rats compared to basal levels. However, insulin stimulated IRS-1 tyrosine phosphorylation was 1.8 -fold higher in endurance-trained rats compared to the sedentary animals (Luciano et al., 2002). Differences in IRS tyrosine phosphorylation are not attributed to differences in IRS content (Bjornholm et al., 1997). Furthermore, exercise training does not seem to result in differences in IRS-1 content and may even attenuate IRS-2 expression (Luciano et al., 2002; Wadley et al., 2001). Therefore, to summarize these data, there is no difference between basal and insulin stimulated IRS-1 tyrosine phosphorylation in $\mathrm{T} 2 \mathrm{D}$; there is a six-fold difference between basal and insulin-stimulated IRS-1 tyrosine phosphorylation in the sedentary group and an 11-fold (6- $\times 1.8$-fold increases, as above) difference between basal and insulinstimulated IRS-1 tyrosine phosphorylation in the exercise-trained group (experimental group distinctions are further illustrated in Figure 1).

Similar to insulin-stimulated IRS-1 phosphorylation, insulin-stimulated IRS1-associated PI3K activity in human skeletal muscle was absent in T2D subjects, increased two-fold in a presumably sedentary control group (no physical activity levels were reported, Bjornholm et al., 1997) and in a true sedentary group (Kirwan et al., 2000), and rose four-fold in the aerobically trained group (Kirwan et al., 2000). Therefore, we submit that sedentary animals/humans are inappropriate controls when studying the roles of IRS-1 and PI3K in T2D. 


\section{Conclusion}

It is in the best interest of everyone to focus on disease prevention to both alleviate the burden of chronic disease on the public health system and to improve the quality of life of the world's population. Although the evidence suggests that sedentary living causes increases in the prevalence of chronic disease and premature death, delineation of the molecular mechanisms of physical inactivity-induced chronic disease is essential for detecting early biomarkers of disease and appropriate preventative exercise prescription. In this review we provided evidence that the sedentary group often used in T2D research is an inappropriate control because an active control group is more healthy. For example, compared to inactive subjects, active control subjects had increased GLUT4 content and insulin-mediated glucose uptake, which have been previously interpreted as unchanged during the onset of T2D as compared to sedentary subjects. Moreover, optimal IRS-1 tyrosine phosphorylation and IRS-1-associated PI3K activity, which have been shown to be completely defective in T2D, have been underestimated due to the use of sedentary subjects, instead of active, more healthy subjects for comparison. Furthermore, impaired glucose tolerance is not an inevitable consequence of aging, but rather, physical inactivity is a cause of insulin resistance with aging.

Therefore, exercise physiology needs to redesignate the sicker sedentary population (as does the rest of the medical profession) to the unhealthy experimental treatment group, and assign the healthy physically active population as normal or control. We challenge others to find ways to express in their own terms the critical importance of understanding the mechanisms by which physical inactivity causes disease and the alternative mechanisms by which exercise reverses the mechanisms of physical inactivity.

\section{Acknowledgments}

Supported by NIH AR19393.

\section{References}

Andersen, P.H., Lund, S., Vestergaard, H., Junker, S., Kahn, B.B., and Pedersen, O. (1993), Expression of the major insulin regulatable glucose transporter (GLUT4) in skeletal muscle of noninsulin-dependent diabetic patients and healthy subjects before and after insulin infusion. J. Clin. Endocrinol Metab. 77: 27-32.

Astrand, P., and Rodahl, K. (1986). Our biological heritage. In: D.B. Van Dalen (Ed.), Textbook of Work Physiology: Physiological Basis of Exercise (3rd ed.), pp. 1-11. New York: McGraw-Hill.

Bjerregaard, P., and Dyerberg, J. (1988). Mortality from ischaemic heart disease and cerebrovascular disease in Greenland. Int. J. Epidemiol. 17: 514-519.

Bjornholm, M., Kawano, Y., Lehtihet, M., and Zierath, J.R. (1997). Insulin receptor substrate-1 phosphorylation and phosphatidylinositol 3-kinase activity in skeletal muscle from NIDDM subjects after in vivo insulin stimulation. Diabetes 46: 524-527.

Caro, J.F., Sinha, M.K., Raju, S.M., Ittoop, O., Pories, W.J., Flickinger, E.G., Meelheim, D., and Dohm, G.L. (1987). Insulin receptor kinase in human skeletal muscle from obese subjects with and without noninsulin dependent diabetes. J. Clin. Invest. 79: 1330-1337. 
Centers for Disease Control and Prevention. Physical Activity and Good Nutrition: Essential Elements to Prevent Chronic Diseases and Obesity-at a Glance (2003). http:/l www.cdc.gov/nccdphp/aag/aag dnpa.htm

Chakravarthy, M.V., and Booth, F.W. (2003). Exercise. Philadelphia: Elsevier.

Cheatham, B., and Kahn, C.R. (1995). Insulin action and the insulin signaling network. Endocr. Rev. 16: 117-142.

Clastres, P. (1972). The Guayaki. In: M.G. Bicchieri (Ed.), Hunters and Gatherers Today, pp. 138-174. New York: Holt, Rinehart and Winston

Cordain, L., Gotshall, R.W., and Eaton, S.B. (1997). Evolutionary aspects of exercise. World Rev. Nutr. Diet 81: 49-60.

Craig, C.L., Russell, S.J., Cameron, C., and Beaulieu, A. (1999). Foundation for Joint Action: Reducing Physical Inactivity. Ottawa: Canadian Fitness and Lifestyle Research Institute.

Denissenko, M., Pao, A., Tang, M., and Pfeifer, G.P. (1996). Preferential formation of benzo[a]pyrene adducts at lung cancer mutational hotspots in p53. Science 18: 430-432.

Diamond, J. (2003) The double puzzle of diabetes. Nature 423: 599-602.

Dietz, W.H., Jr., and Gortmaker, S.L. (1985). Do we fatten our children at the television set? Obesity and television viewing in children and adolescents. Pediatrics 75: 807-812.

Elmendorf, J.S. (2002). Signals that regulate GLUT4 translocation. J. Membr. Biol. 190: 167-174.

Friedman, J.E., Dohm, G.L., Leggett-Frazier, N., Elton, C.W., Tapscott, E.B., Pories, W.P., and Caro, J.F. (1992). Restoration of insulin responsiveness in skeletal muscle of morbidly obese patients after weight loss. Effect on muscle glucose transport and glucose transporter GLUT4. J. Clin. Invest. 89: 701-705.

Garvey, W.T., Maianu, L., Hancock, J.A., Golichowski, A.M., and Baron, A. (1992). Gene expression of GLUT4 in skeletal muscle from insulin-resistant patients with obesity, IGT, GDM, and NIDDM. Diabetes 41: 465-475.

Glanville, E.V., and Geerdink, R.A. (1970). Skinfold thickness, body measurements and age changes in Trio and Wajana Indians of Surinam. Am. J. Phys. Anthropol. 32: 455-461.

Hahn, R.A., Teutsch, S.M., Rothenberg, R.B., and Marks, J.S. (1990). Excess deaths from nine chronic diseases in the United States (1986). JAMA 264: 2654-2659.

Hamdy, O., Goodyear, L.J., and Horton, E.S. (2001). Diet and exercise in type 2 diabetes mellitus. Endocrinol. Metab. Clin. North Am. 30: 883-907.

Heath, G.W., Gavin, J.R., 3rd, Hinderliter, J.M., Hagberg, J.M., Bloomfield, S.A., and Holloszy, J.O. (1983). Effects of exercise and lack of exercise on glucose tolerance and insulin sensitivity. J. Appl. Physiol. 55: 512-517.

Henriksen, E.J. (2002). Invited review: Effects of acute exercise and exercise training on insulin resistance. J. Appl. Physiol. 93: 788-796.

Hoffman, C., Rice, D., and Sung, H.Y. (1996). Persons with chronic conditions. Their prevalence and costs. JAMA 276: 1473-1479.

Hu, F.B., Sigal, R.J., Rich-Edwards, J.W., Colditz, G.A., Solomon, C.G., Willett, W.C., Speizer, F.E., and Manson, J.E. (1999). Walking compared with vigorous physical activity and risk of type 2 diabetes in women: A prospective study. JAMA 282: 1433-1439.

Hu, F.B., Stampfer, M.J., Colditz, G.A., Ascherio, A., Rexrode, K.M., Willett, W.C., and Manson, J.E. (2000). Physical activity and risk of stroke in women. JAMA 283: 2961-2967. 
Joffe, B.I., Jackson, W.P., Thomas, M.E., Toyer, M.G., Keller, P., and Pimstone, B.L. (1971). Metabolic responses to oral glucose in the Kalahari Bushmen. Br. Med. J. 4: 206-208.

Kim, Y.B., Inoue, T., Nakajima, R., Shirai-Morishita, Y., Tokuyama, K., and Suzuki, M. (1999a). Effect of long-term exercise on gene expression of insulin signaling pathway intermediates in skeletal muscle. Biochem. Biophys. Res. Commun. 254: 720-727.

Kirwan, J.P., del Aguila, L.F., Hernandez, J.M., Williamson, D.L., O'Gorman, D.J., Lewis, R., and Krishnan, R.K. (2000). Regular exercise enhances insulin activation of IRS1-associated PI3-kinase in human skeletal muscle. J. Appl. Physiol. 88: 797-803.

Kraus, H., and Raab, W. (1961). Hypokinetic Disease. Springfield, IL: C.C Thomas.

Kromann, N., and Green, A. (1980). Epidemiological studies in the Upernavik district, Greenland. Incidence of some chronic diseases 1950-1974. Acta. Med. Scand. 208: $401-406$.

Kuroshima, A., Itoh, S., Azuma, T., and Agishi, Y. (1972). Glucose tolerance test in the Ainu. Int. J. Biometeorol. 16: 193-197.

Langfort, J., Viese, M., Ploug, T., and Dela, F. (2003). Time course of GLUT4 and AMPK protein expression in human skeletal muscle during one month of physical training. Scand. J. Med. Sci. Sports 13: 169-174.

Lederman, J.M., Wallace, A.C., and Hildes, J.A. (1962). Atheriosclerosis and neoplasms in Canadian Eskimos. In: N.W. Shock (Ed.), Biological Aspects of Aging: Proceedings of the Fifth International Congress on Gerontology, pp. 201-207. New York: Columbia University Press.

Lemieux, K., Konrad, D., Klip, A., and Marette, A. (2003). The AMP-activated protein kinase activator AICAR does not induce GLUT4 translocation to transverse tubules but stimulates glucose uptake and p38 mitogen-activated protein kinases alpha and beta in skeletal muscle. FASEB J. 17: 1658-1665.

Licinio, J., Caglayan, S., Ozata, M., Yildiz, B.O., De Miranda, P.B., O'Kirwan, F., Whitby, R., Liang, L., Cohen, P., Bhasin, S., Krauss, RM., Veldhuis, J.D., Wagner, A.J., DePaoli, A.M., McCann, S.M., and Wong, M.L. (2004). Phenotypic effects of leptin replacement on morbid obesity, diabetes mellitus, hypogonadism, and behavior in leptindeficient adults. Proc. Natl. Acad. Sci. USA [Epub ahead of print].

Lindeberg, S., Eliasson, M., Lindahl, B., and Ahren, B. (1999). Low serum insulin in traditional Pacific Islanders-the Kitava Study. Metabolism 48: 1216-1219.

Luciano, E., Carneiro, E.M., Carvalho, C.R., Carvalheira, J.B., Peres, S.B., Reis, M.A., Saad, M.J., Boschero, A.C., and Velloso, L.A. (2002). Endurance training improves responsiveness to insulin and modulates insulin signal transduction through the phosphatidylinositol 3-kinase/Akt-1 pathway. Eur. J. Endocrinol. 147: 149-157.

Manson, J.E., Hu, F.B., Rich-Edwards, J.W., Colditz, G.A., Stampfer, M.J., Willett, W.C., Speizer, F.E., and Hennekens, C.H. (1999). A prospective study of walking as compared with vigorous exercise in the prevention of coronary heart disease in women. N. Engl. J. Med. 341: 650-658.

Merimee, T.J., Rimoin, D.L., and Cavalli-Sforza, L.L. (1972). Metabolic studies in the African pygmy. J. Clin. Invest. 51: 395-401.

Middaugh, J.P. (1990). Cardiovascular deaths among Alaskan natives, 1980-86. Am. J. Publ. Health 80: 282-285.

Mokdad, A.H., Marks, J.S., Stroup, D.F., and Gerberding, J.L. (2004). Actual causes of death in the United States. (2000). JAMA 291: 1238-1245. 
Pedersen, O., Bak, J.F., Andersen, P.H., Lund, S., Moller, D.E., Flier, J.S., and Kahn, B.B. (1990). Evidence against altered expression of GLUT1 or GLUT4 in skeletal muscle of patients with obesity or NIDDM. Diabetes 39: 865-870.

Perseghin, G., Petersen, K., and Shulman, G.I. (2003). Cellular mechanism of insulin resistance: Potential links with inflammation. Int. J. Obes. Relat. Metab. Disord. 27 (Suppl 3): S6-S11.

Resnick, N.M. (1998). Geriatric medicine. In: A.S. Fauci, E. Braunwald, K.J. Isselbacher, J.D. Wilson, J.B. Martin, D.L. Kasper, S.L. Hauser, and D.L. Longo. Harrison's Principles of Internal Medicine, 14 ed., p. 38. New York: McGraw-Hill

Rode, A., and Shephard, R.J. (1984). Ten years of "civilization": Fitness of Canadian Inuit. J. Appl. Physiol. 56: 1472-1477.

Rode, A., and Shephard, R.J. (1994). Physiological consequences of acculturation: A 20year study of fitness in an Inuit community. Eur. J. Appl. Physiol. Occup. Physiol. 69: 516-524.

Rodnick, K.J., Slot, J.W., Studelska, D.R., Hanpeter, D.E., Robinson, L.J., Geuze, H.J., and James, D.E. (1992). Immunocytochemical and biochemical studies of GLUT4 in rat skeletal muscle. J. Biol. Chem. 267: 6278-6285.

Seals, D.R., Hagberg, J.M., Allen, W.K., Hurley, B.F., Dalsky, G.P., Ehsani, A.A., and Holloszy, J.O. (1984). Glucose tolerance in young and older athletes and sedentary men. J. Appl. Physiol. 56: 1521-1525.

Slentz, C.A., Gulve, E.A., Rodnick, K.J., Henriksen, E.J., Youn, J.H., and Holloszy, J.O. (1992). Glucose transporters and maximal transport are increased in endurance-trained rat soleus. J. Appl. Physiol. 73: 486-492.

Somwar, R., Perreault, M., Kapur, S., Taha, C., Sweeney, G., Ramlal, T., Kim, D.Y., Keen, J., Cote, C.H., Klip, A., and Marette, A. (2000). Activation of p38 mitogen-activated protein kinase alpha and beta by insulin and contraction in rat skeletal muscle: Potential role in the stimulation of glucose transport. Diabetes 49: 1794-1800.

Spielman, R.S., Fajans, S.S., Neel, J.V., Pek, S., Floyd, J.C., and Oliver, W.J. (1982). Glucose tolerance in two unacculturated Indian tribes of Brazil. Diabetologia 23: 90-93.

Tomas, E., Lin, Y.S., Dagher, Z., Saha, A., Luo, Z., Ido, Y., and Ruderman N.B. (2002). Hyperglycemia and insulin resistance: Possible mechanisms. Ann. NY Acad. Sci. 967: 43-51.

Wadley, G.D., Tunstall, R.J., Sanigorski, A., Collier, G.R., Hargreaves, M., and CameronSmith, D. (2001). Differential effects of exercise on insulin-signaling gene expression in human skeletal muscle. J. Appl. Physiol. 90: 436-440.

Wallberg-Henriksson, H., Rincon, J., and Zierath, J.R. (1998). Exercise in the management of non-insulin-dependent diabetes mellitus. Sports Med. 25: 25-35.

World Health Organization. (2002). Physical inactivity a leading cause of disease and disability, warns WHO. http://www.who.int/inf/en/pr-2002-23.html

World Health Organization. (2004). Global Strategy on Diet, Physical Activity and Health. http://www.who.int/hpr/global.strategy.shtml

Zierath, J.R., He, L., Guma, A., Odegoard Wahlstrom, E., Klip, A., and Wallberg-Henriksson, H. (1996). Insulin action on glucose transport and plasma membrane GLUT4 content in skeletal muscle from patients with NIDDM. Diabetologia 39: 1180-1189.

Zierath, J.R., Krook, A., and Wallberg-Henriksson, H. (1998). Insulin action in skeletal muscle from patients with NIDDM. Mol. Cell. Biochem. 182: 153-160.

Received March 2, 2004; accepted in final form April 30, 2004. 
Copyright of Canadian Journal of Applied Physiology is the property of Human Kinetics Publishers, Inc. and its content may not be copied or emailed to multiple sites or posted to a listserv without the copyright holder's express written permission. However, users may print, download, or email articles for individual use. 